\title{
Association between infant feeding patterns and diarrhoeal and respiratory illness: A cohort study in Chittagong, Bangladesh Seema Mihrshahi*1, Wendy H Oddy ${ }^{2}$, Jennifer K Peat ${ }^{3}$ and Iqbal Kabir ${ }^{4}$
}

\begin{abstract}
Address: ${ }^{1}$ Department of Medicine, University of Melbourne, The Royal Melbourne Hospital, Parkville, Victoria, Australia, ${ }^{2}$ The Telethon Institute for Child Health, Centre for Child Health Research and University of Western Australia, Western Australia, Australia, ${ }^{3}$ Independent Research Consultant, Tomerong, New South Wales, Australia and ${ }^{4}$ International Centre for Diarrhoeal Diseases Research, Bangladesh
\end{abstract}

Email: Seema Mihrshahi* - smihrshahi@yahoo.com; Wendy H Oddy - wendyo@ichr.uwa.edu.au; Jennifer K Peat - jennypeat@optusnet.com.au; Iqbal Kabir - ikabir@icddrb.org

* Corresponding author

Published: 24 November 2008

International Breastfeeding Journal 2008, 3:28 doi:10.1 186/1746-4358-3-28
Received: 9 January 2008

Accepted: 24 November 2008

This article is available from: http://www.internationalbreastfeedingjournal.com/content/3/l/28

(C) 2008 Mihrshahi et al; licensee BioMed Central Ltd.

This is an Open Access article distributed under the terms of the Creative Commons Attribution License (http://creativecommons.org/licenses/by/2.0), which permits unrestricted use, distribution, and reproduction in any medium, provided the original work is properly cited.

\begin{abstract}
Background: In developing countries, infectious diseases such as diarrhoea and acute respiratory infections are the main cause of mortality and morbidity in infants aged less than one year. The importance of exclusive breastfeeding in the prevention of infectious diseases during infancy is well known. Although breastfeeding is almost universal in Bangladesh, the rates of exclusive breastfeeding remain low. This cohort study was designed to compare the prevalence of diarrhoea and acute respiratory infection (ARI) in infants according to their breastfeeding status in a prospective cohort of infants from birth to six months of age.
\end{abstract}

Methods: A total of 35I pregnant women were recruited in the Anowara subdistrict of Chittagong. Breastfeeding practices and the 7-day prevalence of diarrhoea and ARI were recorded at monthly home visits. Prevalences were compared using chi-squared tests and logistic regression.

Results: A total of 272 mother-infant pairs completed the study to six months. Infants who were exclusively breastfed for six months had a significantly lower 7-day prevalence of diarrhoea [AOR for lack of $E B F=2.50(95 \% \mathrm{Cl} I .10,5.69), \mathrm{P}=0.03]$ and a significantly lower 7-day prevalence of ARI [AOR for lack of EBF $=2.3 \mathrm{I}(95 \% \mathrm{Cl} \mathrm{I.33,4.00),} \mathrm{P}<0.0 \mathrm{I}]$ than infants who were not exclusively breastfed. However, when the association between patterns of infant feeding (exclusive, predominant and partial breastfeeding) and illness was investigated in more detail, there was no significant difference in the prevalence of diarrhoea between exclusively $[6.6 \%(95 \% \mathrm{Cl} 2.8,10.4)]$ and predominantly breastfed infants $[3.7 \%(95 \% \mathrm{Cl} 0.09,18.3),(\mathrm{p}=0.56)]$. Partially breastfed infants had a higher prevalence of diarrhoea than the others [19.2\% (95\% Cl 10.4, 27.9), $(p=0.01)]$. Similarly, although there was a large difference in prevalence in acute respiratory illness between exclusively $[54.2 \%(95 \% \mathrm{Cl} 46.6,61.8)]$ and predominantly breastfed infants $[70.4 \%(95 \% \mathrm{Cl} 53.2$, 87.6)] there was no significant difference in the prevalence $(p=0.17)$.

Conclusion: The findings suggest that exclusive or predominant breastfeeding can reduce rates of morbidity significantly in this region of rural Bangladesh. 


\section{Background}

In Bangladesh, infectious diseases such as diarrhoea and acute respiratory infections are the main cause of mortality and morbidity in infants aged less than one year $[1,2]$. The importance of breastfeeding in the prevention of infectious diseases during infancy is well known $[3,4]$. Although breastfeeding is almost universal in Bangladesh, the rates of exclusive breastfeeding remain low. Recent data show that only $38 \%$ of children aged 2-3 months are exclusively breastfed and $23 \%$ of children are given complementary foods before the sixth month [2]. Previous studies conducted in urban areas of Bangladesh using individual peer counseling have shown significant increases in the rates of exclusive breastfeeding [5]. The Chittagong peer counseling study was a randomized trial undertaken to assess the impact of group and individual peer counseling on exclusive breastfeeding rates in Anowara, a rural area of Chittagong district [6]. The study was conducted by staff from International Centre for Diarrhoeal Diseases Research, Bangladesh (ICDDR, B) from 1999 to 2001. The peer counseling study was designed to compare the effectiveness of individual versus group counseling in achieving improved exclusive breastfeeding rates. This paper presents the results of a secondary analysis of the data where the data were analyzed without regard to randomization group. The main aim of this analysis was to measure the association between exclusive breastfeeding and infectious disease (diarrhoea and acute respiratory illness) in a cohort of women and children followed from birth until six months of age.

\section{Methods}

\section{Study design and setting}

The study was conducted from September 1999 to March 2001 in three unions of Anowara thana (sub district) in Chittagong district, a rural area in south eastern Bangladesh approximately $40 \mathrm{~km}$ from Chittagong City.

The main study was a randomized controlled intervention trial where pregnant women in two of the unions were randomized to the intervention (group or individual peer counseling) and one union was used as a control group. The details of this study including the sample size and CONSORT diagram have been presented [6]. For the purposes of this analysis, the data are analyzed as a cohort study with infants followed up from birth to six months of age.

\section{Recruitment and inclusion and exclusion criteria}

A total of 351 pregnant women were recruited and 272 mother infant pairs completed the study to six months (Figure 1). Pregnant women aged 16-35 years, with no more than three living children or a parity of five, who intended to deliver and stay in the study area were asked to participate. Women with documented heart disease, insulin dependent diabetes mellitus, or eclampsia during the previous pregnancy were excluded. Infants were excluded from the study if they had congenital abnormalities; were admitted to intensive care after birth; were twins/triplets or had weight below $1800 \mathrm{~g}$ on the fourth day after birth.

\section{Data collection and definitions}

An interviewer visited each mother-infant pair at home eight times during the study period. Data on socioeconomic, demographic and environmental variables, maternal and pregnancy factors, and previous infant feeding practices were obtained at enrolment. Details of delivery and early infant feeding were collected on the fourth day after birth. Thereafter, information on infant feeding and illness was obtained monthly until the infant was six months of age.

At each home visit, infant feeding status was assessed using 24 hour recall. In addition to this the mother was asked if she had fed her baby anything other than breast milk since the last visit. If she had fed anything else on two successive days or more, the information was taken into consideration when classifying the feeding status as exclusive, predominant, partial or no breastfeeding. Definitions used in the study:

- Exclusive breastfeeding was defined when the infant received breast milk only and no other solids or liquids with the exception of vitamins, minerals, medicines or oral rehydration solution;

- Predominant breastfeeding was defined when the infant received breast milk and water, water based liquids such as sugar water and juices but not infant formula or milk;

- Partial breastfeeding was defined when the infant received breast milk in addition to complementary foods;

- Non-breastfed was when the infant received no breast milk;

- Complementary foods included milk, infant formula, gruel or semi-solid foods given in addition to breast milk;

- Prelacteal foods refer to non-breast milk feeds given before breastfeeding is initiated such as honey and mustard oil.

Definitions of primary outcomes:

- Diarrhoea was defined as three or more loose stools in 24 hours in the past week (seven days) at any monthly visit during the first six months of life; 


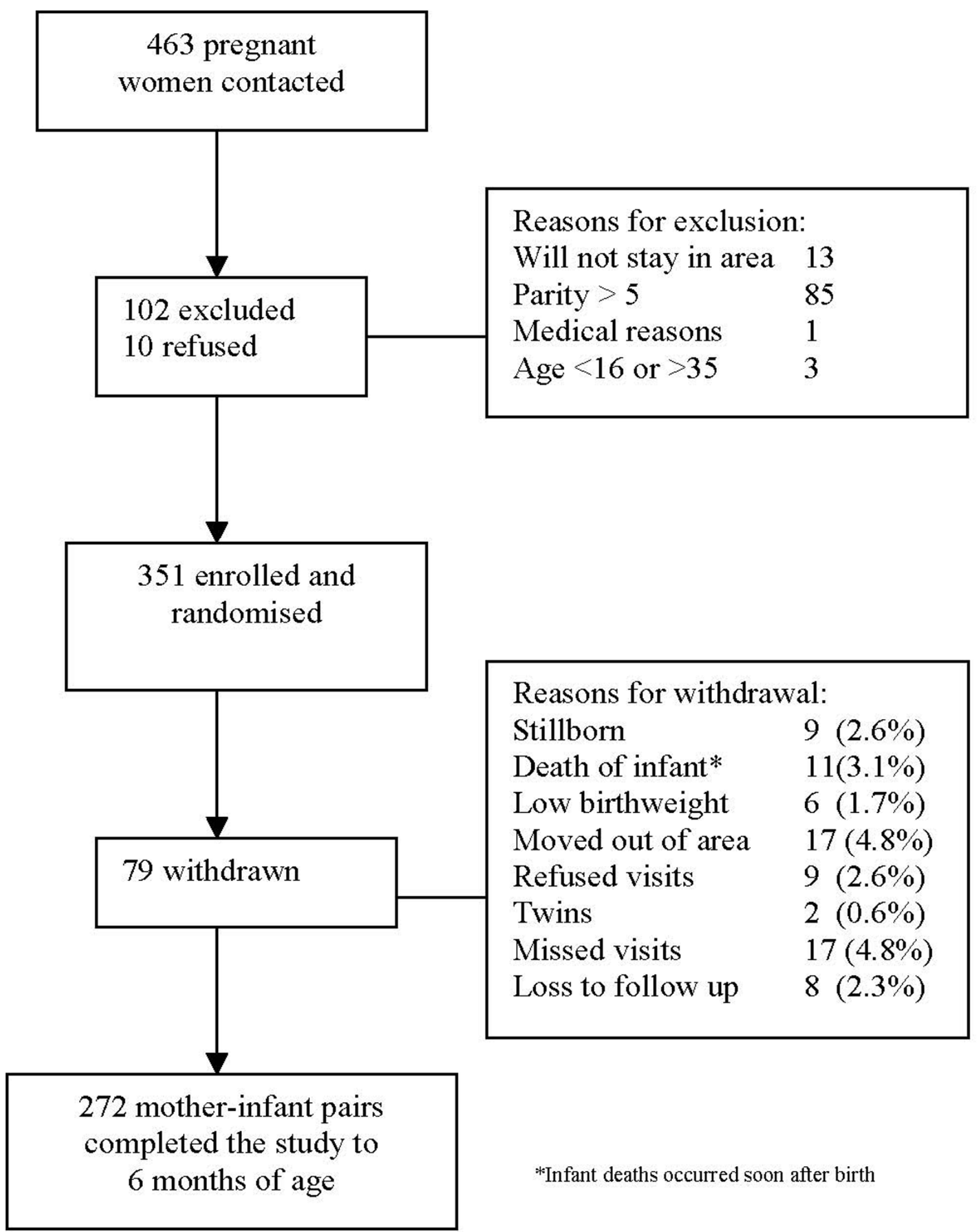

Figure I

Chittagong cohort study trial profile. 
- Acute respiratory infection was defined as cough and fever in the past week (seven days) at any monthly visit during the first six months of life.

\section{Ethics approval}

Ethical approval for the randomized trial was obtained from the Ethical Review Committee of the ICDDR, B. Signed, informed consent was obtained from each mother and her husband or guardian. Ethics approval for the secondary analysis was obtained by Human Research Ethics Committee of Curtin University and ICDDR, B.

\section{Data analyses}

Statistical analyses were conducted using SPSS (version 13.0). The primary outcome variables were the 7-day prevalence of diarrhoea and acute respiratory illness at any monthly visit in the first six months of life (ie. analysis was conducted by infant and not by number of episodes). Explanatory variables were exclusive, predominant, partial and no breastfeeding, categorized at the six month visit. The breastfeeding variable was also dichotomized as exclusive breastfeeding or not exclusive breastfeeding (which included predominant, partial and no breastfeeding) at the six month visit. Chi-squared tests and logistic regression were used to test associations. Core confounders such as infant's gender, mother's education and work status, number of siblings, latrine type, assets and drinking water source were left in the final model. Other possible confounders such as mother's age, father's education and occupation, house type, house ownership, and mother's height and weight and intervention group were included in the model if they changed the standard error by $5 \%$ or more. Results are presented as odds ratios and adjusted odds ratios.

\section{Results}

A total of 463 pregnant women were contacted for entry into the trial and 122 women fulfilled the exclusion criteria. A total of 351 women were enrolled and randomized into the main trial. Of these women, 272 (77.5\%) completed the study to six months. Figure 1 shows the trial profile and reasons for exclusion and loss to follow up.

\section{Baseline characteristics of the study population}

Table 1 shows the baseline characteristics in families who completed the study to six months. The mean number of members in each household was 5.64 (SD 3.31). A total of $53.7 \%$ of households had more than five members. Mean age of the women was 22.63 years (SD 4.4). On average men went to school for longer than women and most were in some form of paid employment. A majority of families (84\%) owned their own dwelling and had access to a latrine which was shared with other families.

There were some differences between families in the study and those who were withdrawn $(\mathrm{n}=79)$. Families who
Table I: Baseline characteristics of families in the study ( $N=$ 272)

\begin{tabular}{|c|c|c|c|}
\hline Characteristic & & $\mathbf{n}$ & $\%$ \\
\hline \multirow[t]{3}{*}{ Total household members } & $\mathrm{I}-2$ & 17 & 6.3 \\
\hline & $3-4$ & 109 & 40.1 \\
\hline & 5 or more & 146 & 53.6 \\
\hline \multirow{4}{*}{ Husband resides } & In same house & 209 & 76.8 \\
\hline & Separated & 3 & 1.1 \\
\hline & Lives abroad & 29 & 10.7 \\
\hline & Comes and goes & 31 & 10.4 \\
\hline \multirow[t]{4}{*}{ Mother's age } & $16-20$ & 101 & 37.1 \\
\hline & $21-25$ & 106 & 39.0 \\
\hline & $26-30$ & 49 & 18.0 \\
\hline & $31-35$ & 16 & 5.9 \\
\hline \multirow[t]{3}{*}{ Parity } & One & 79 & 29.0 \\
\hline & Two & 69 & 25.4 \\
\hline & Three or more & 124 & 45.6 \\
\hline \multirow[t]{2}{*}{ Antenatal care } & Yes & 109 & 40.1 \\
\hline & No & 163 & 59.9 \\
\hline \multirow[t]{3}{*}{ Mother's education } & None & 125 & 46.0 \\
\hline & Primary & 60 & 22.0 \\
\hline & Secondary and above & 87 & 32.0 \\
\hline \multirow[t]{3}{*}{ Father's education } & None & 96 & 35.3 \\
\hline & Primary & 77 & 28.3 \\
\hline & Secondary and above & 99 & 36.4 \\
\hline
\end{tabular}

completed the study were more likely to have husbands/ fathers who lived at home than families who withdrew $(77 \%$ vs $65 \%, p=0.03)$. Families who completed the study to six months were also more likely to have other children $(66 \%$ vs $48 \%, \mathrm{p}<0.01)$ and more children in the household in total than families who withdrew (chisquare for trend $=6.757, \mathrm{p}<0.01$ ). However, the overall number of household members was comparable between groups. Families who completed the study to six months were more likely to own their own house than those who were withdrawn ( $89 \%$ vs $81 \%, p=0.049)$. There were no differences in maternal weight, height or underarm circumference, education status, occupation or household income between the groups.

Table 2 shows the delivery and birth characteristics of the babies in the study and those babies who were withdrawn or lost to follow up. A total of nine babies were stillborn. The gestational age was not different between groups. However, babies' weight on day four was significantly less in the group who withdrew $(\mathrm{p}<0.01)$ as was the length ( $\mathrm{p}$ $<0.01$ ). Most babies were delivered vaginally, at home, by untrained dais or birth attendants. There were no differences in delivery characteristics or babies' gender between groups. 
Table 2: Comparison of delivery characteristics between infants in study and those who were withdrawn

\begin{tabular}{|c|c|c|c|c|}
\hline & \multicolumn{2}{|r|}{ Completed study } & \multicolumn{2}{|r|}{ Withdrawn } \\
\hline & $\mathbf{N}$ & Mean (SD) or n (\%) & $\mathbf{N}$ & Mean (SD) or n (\%) \\
\hline $\begin{array}{l}\text { Gestational age (weeks) } \\
\text { Mean (SD) }\end{array}$ & 272 & $39.1(2.8)$ & 70 & $39.5(3.4)$ \\
\hline $\begin{array}{l}\text { Weight on day } 4 \text { (kg) } \\
\text { Mean (SD) }\end{array}$ & 246 & $2.7(0.4)$ & 51 & $2.5(0.5)$ \\
\hline $\begin{array}{l}\text { Length on day } 4(\mathrm{~cm}) \\
\text { Mean (SD) }\end{array}$ & 244 & $47.5(1.9)$ & 51 & $46.6(2.9)$ \\
\hline Place of delivery & 272 & & 70 & \\
\hline home & & $240(88.2 \%)$ & & $63(90 \%)$ \\
\hline hospital/clinic & & $32(11.8 \%)$ & & $7(10 \%)$ \\
\hline Type of delivery & 272 & & 70 & \\
\hline normal vaginal & & $268(98.5 \%)$ & & $67(95.7 \%)$ \\
\hline vaginal assisted & & - & & $\mathrm{I}(\mathrm{I} .4 \%)$ \\
\hline caesarean section & & $4(1.5 \%)$ & & $2(2.9 \%)$ \\
\hline Baby delivered by & 272 & & 70 & \\
\hline trained birth attendant & & $26(9.6 \%)$ & & $4(5.7 \%)$ \\
\hline untrained attendant & & $155(57.0 \%)$ & & $36(51.4 \%)$ \\
\hline experienced relative & & $43(15.8 \%)$ & & $15(21.4 \%)$ \\
\hline nurse or doctor & & $12(4.4 \%)$ & & $10(14.3 \%)$ \\
\hline family welfare visitor & & $29(10.7 \%)$ & & $5(7.1)$ \\
\hline other & & $7(2.6 \%)$ & & - \\
\hline Baby's gender & 272 & & 70 & \\
\hline male & & $127(46.7 \%)$ & & 37 (52.9\%) \\
\hline female & & 145 (53.3\%) & & $33(47.1 \%)$ \\
\hline
\end{tabular}

Values are mean (SD), number (\%)

\section{Infant feeding practices}

Table 3 shows the early feeding practices of the infants in the cohort who completed the study. All babies were fed colostrum, therefore breastfeeding was initiated within three days of birth in all cases and commonly within three hours of birth. However, in $70 \%$ of cases colostrum was not the first food given to the child and other prelacteal foods were given, the most common being mustard oil or honey. The most common reason for feeding of prelacteal foods was that it was a custom or tradition to do so.

Figure 2 shows the distribution of breastfeeding patterns by age of the child. If prelacteal foods were excluded from the analysis, there was a high rate of exclusive breastfeeding throughout the study with $87.1 \%$ of mothers exclusively breastfeeding at one month. The rate of exclusive breastfeeding gradually declined to $77.2 \%$ at three months and $61.4 \%$ at six months. Because of the rigorous methods of classification, once a woman was categorised in the predominant breastfeeding category she was not reclassified as exclusively breastfeeding and similarly if a woman was categorised as partially breastfeeding she was not reclassified as predominantly breastfeeding at subsequent visits. At the six month visit a total of 167 (61.4\%) of infants were exclusively breastfed, 27 (9.9\%) infants were predominantly breastfed and 77 (28.3\%) infants were partially breastfed. Only one child was not breastfed in the entire cohort.

\section{Prevalence of illness episodes}

Table 4 shows the numbers of illness episodes in the previous seven days at each visit. The 7 -day cumulative prevalence of diarrhoea at each monthly visit in the first six months was $9.9 \%$ (27/272), of ARI was $61.7 \%(168 / 272)$ and of any illness was $95.6 \%$ (260/272).

\section{Prevalence of illness between exclusively breastfed and non-exclusively breastfed infants and association with infant feeding patterns}

Figure 3 shows the difference in prevalence of diarrhoea and acute respiratory infection between infants who were and who were not exclusively breastfed for at least six months. The group who were exclusively breastfed for six months had an $8.6 \%$ lower 7 -day prevalence of diarrhoea and a $20 \%$ lower 7 -day prevalence of ARI than the group who were not exclusively breastfed. There was a significant association between the lack of exclusive breastfeeding and diarrhoea and acute respiratory infection in the groups. These significant differences remained even after adjustment for mother's education, asset score and husband living at home as a measure of socioeconomic status, type of latrine as a measure of sanitation, gender and other siblings. The adjusted odds ratio for diarrhoea is $2.50(95 \%$ CI 1.10, 5.69) and for acute respiratory infection is 2.31 (95\% CI 1.33, 4.00).

The association between patterns of infant feeding (exclusive, predominant and partial breastfeeding at six 
Table 3: Early feeding practices in Chittagong cohort $(\mathrm{N}=\mathbf{2 7 2})$

\begin{tabular}{|c|c|c|}
\hline & $\mathbf{n}$ & $\%$ \\
\hline \multicolumn{3}{|l|}{ First food given to child } \\
\hline colostrum & 80 & 29.4 \\
\hline honey & 45 & 16.5 \\
\hline misri/sugar water & 8 & 2.9 \\
\hline honey + mustard oil & 2 & 0.7 \\
\hline water & 19 & 7.0 \\
\hline mustard oil & 82 & 30.1 \\
\hline powder milk & 2 & 0.7 \\
\hline other & 34 & 12.5 \\
\hline \multicolumn{3}{|c|}{ Reason for feeding prelacteal foods* } \\
\hline sweet voice & 3 & 1.6 \\
\hline satisfy hunger & 13 & 6.8 \\
\hline prevent cold & 3 & 1.6 \\
\hline clean stomach/mouth/throat & 54 & 28.1 \\
\hline tradition & 116 & 60.4 \\
\hline stop baby crying & 2 & 1.0 \\
\hline colostrum insufficient & I & 0.5 \\
\hline mother sick & 5 & 2.6 \\
\hline baby didn't suckle & 3 & 1.6 \\
\hline other & 4 & 2.1 \\
\hline \multicolumn{3}{|l|}{ Initiation of breastfeeding } \\
\hline within I hr & 62 & 22.8 \\
\hline within $2 \mathrm{hrs}$ & 82 & 30.1 \\
\hline within $3 \mathrm{hrs}$ & 17 & 6.3 \\
\hline $4-6 \mathrm{hrs}$ & 31 & 11.4 \\
\hline $7-12 \mathrm{hrs}$ & 30 & 11.0 \\
\hline I2-24 hrs & 18 & 6.6 \\
\hline$>24 \mathrm{hrs}$ & 30 & 11.0 \\
\hline missing & 2 & 0.7 \\
\hline
\end{tabular}

*Sample size for this variable was 192

months) and illness was investigated, and the prevalences are shown in Figure 4 . The number of predominantly breastfed infants was low $(\mathrm{n}=27)$ and hence the confidence intervals are large. There was no significant difference in the prevalence of diarrhoea between exclusively [Diarrhoea prevalence $6.6 \%(95 \%$ CI $2.8,10.4)$ ] and predominantly breastfed infants [Diarrhoea prevalence 3.7\% (95\% CI 0.09, 18.3), ( $\mathrm{p}=0.56)]$, however partially breastfed infants had a higher prevalence of diarrhoea than the others [Diarrhoea prevalence 19.2\% (95\% CI 10.4, 27.9), $(p=0.01)]$. Similarly, although there was a large difference in prevalence in acute respiratory illness between exclusively [ARI prevalence $54.2 \%$ (95\%CI 46.6, 61.8)] and predominantly breastfed infants [ARI prevalence $70.4 \%$ (95\%CI 53.2, 87.6)] there was no significant difference in the prevalence $(\mathrm{p}=0.17)$. Partially breastfed infants had a significantly higher prevalence [ARI prevalence $77.4 \%(95 \%$ CI $67.3,85.0)]$ and the data showed a significant trend of breastfeeding patterns on ARI ( $\mathrm{p}$ value for trend $<0.01)$. Combining the exposure and outcome into three monthly observations to avoid misclassification showed similar results (data not shown).
The multivariate analysis showed similar results. Exclusive breastfeeding was not significantly more protective than predominant breastfeeding for diarrhoeal illness but was significantly more protective than partial breastfeeding. Similarly exclusive breastfeeding was not significantly more protective than predominant breastfeeding for acute respiratory infection but was significantly more protective than partial breastfeeding (Table 5).

\section{Discussion}

This study has shown that in a cohort of infants in rural Bangladesh followed up from birth to six months of age, infants who were exclusively breastfed for six months had a significantly lower 7-day prevalence of diarrhoea [AOR for lack of $\mathrm{EBF}=2.50(95 \%$ CI 1.10, 5.69), $\mathrm{p}=0.03$ ] and a significantly lower 7-day prevalence of ARI [AOR for lack of $\mathrm{EBF}=2.31(95 \%$ CI 1.33, 4.00), $\mathrm{p}<0.01$ ] than infants who were not exclusively breastfed. This effect was significant and remained even after controlling for several potential confounders. However, when the association between patterns of infant feeding (exclusive, predominant and partial breastfeeding) and illness was investigated in more detail, exclusive breastfeeding was not significantly more protective than predominant breastfeeding for preventing diarrhoeal illness although it was significantly more protective than partial breastfeeding. Similarly, exclusive breastfeeding was not significantly more protective than predominant breastfeeding for preventing acute respiratory infection but it was significantly more protective than partial breastfeeding. Partially breastfed infants had other sources of nutrition than breastmilk, with infant formula, other liquids, milks and solid foods part of their regular diet. These findings suggest that predominant breastfeeding may be sufficient to reduce rates of morbidity significantly in this rural area of Bangladesh. However, the number of predominantly breastfed infants was small $(\mathrm{n}=27)$ and further studies with larger numbers would be needed to be certain that there are no differences in these two infectious disease outcomes between exclusively and predominantly breastfed infants.

In a recent study with data from India, Peru and Ghana a similar effect was shown on hospitalizations for diarrhoeal and respiratory illness [7]. There was no significant difference in the risk of hospitalization between infants who were exclusively breastfed compared with infants who were predominantly breastfed [adjusted rate ratio $=$ 0.67 (95\% CI 0.23, 2.01)]. However, non-breastfed infants had a higher risk of all cause hospitalization when compared with infants who had been predominantly breastfed [adjusted rate ratio $=3.39(95 \%$ CI 1.74, 6.61); $\mathrm{p}<0.01]$ and also had a higher diarrhoea specific hospitalization [adjusted rate ratio $=5.59(95 \%$ CI 2.17, 14.4); $\mathrm{p}<0.01$ ]. A similar effect was seen on mortality with no 


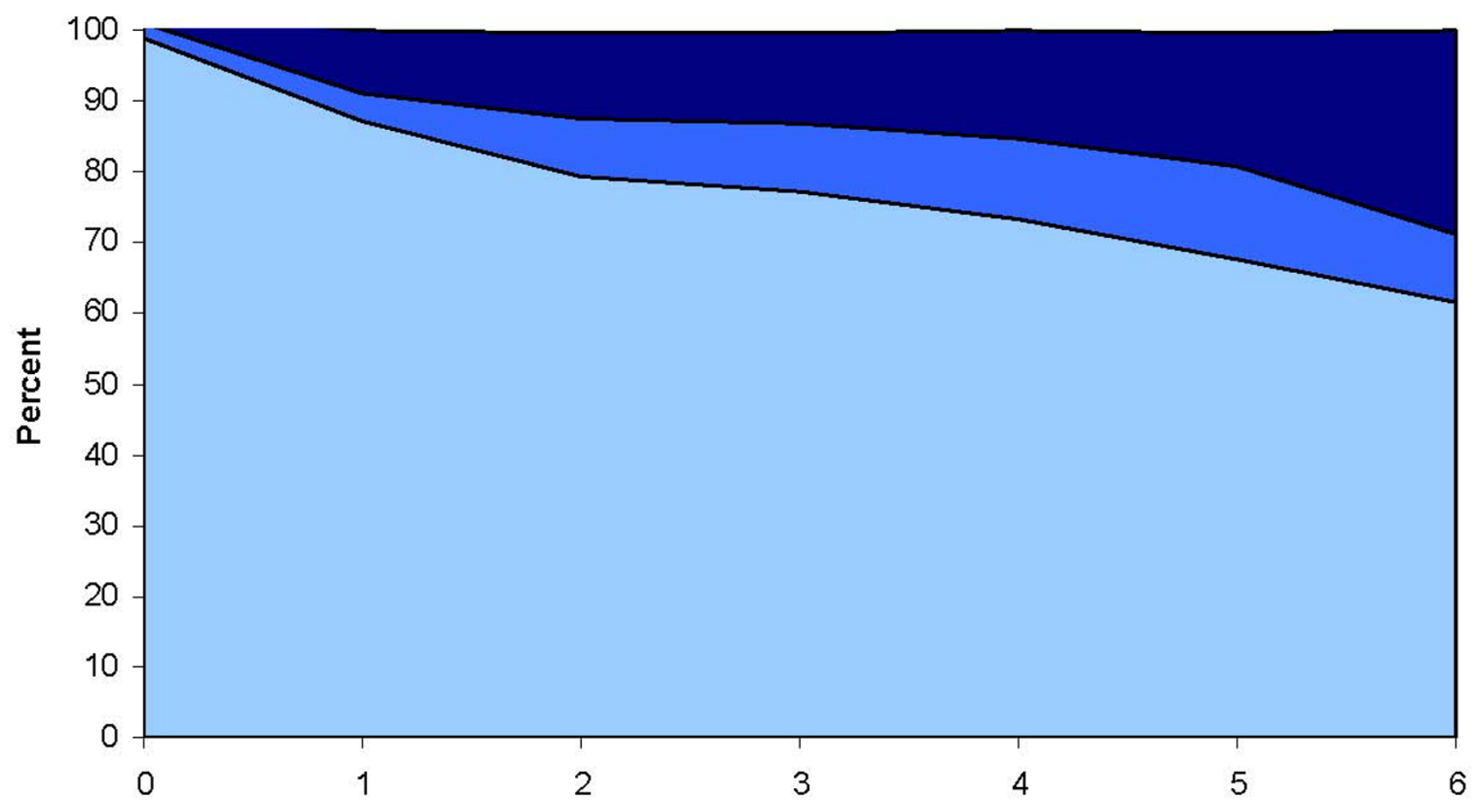

Partial BF

Predominant BF Exclusive BF

\section{Age in months}

\section{Figure 2}

Distribution of breastfeeding (BF) patterns by age in the Chittagong Cohort Study.

significant difference in the risk of death between children who were exclusively breastfed and those who were predominantly breastfed [adjusted hazard ratio $=1.46(95 \%$ CI $0.75,2.86)]$. However, non breastfed infants had a higher risk of dying when compared with infants who had been predominantly breastfed [adjusted hazard ratio = 2.46 (95\% CI 1.44, 4.18)]; $\mathrm{p}<0.01]$. This led the authors to conclude that where rates of predominant breastfeeding are already high, promotion efforts should focus on sustaining these high rates rather than on attempting to achieve a shift from predominant breastfeeding to exclusive breastfeeding [7].

One of the major problems when comparing similarly designed studies in different settings is that infant feeding patterns are not well defined. An advantage in this study was that four levels of infant feeding pattern could be compared. These were non breastfed, partially breastfed, predominantly breastfed and exclusively breastfed and WHO definitions of exclusive and predominant breastfeeding [8] were applied. However, due to the very small

Table 4: Episodes of illness and prevalence in last 7-days at monthly visits in the first six months of life, $n$ (\%)

\begin{tabular}{|c|c|c|c|c|c|}
\hline Visit & Diarrhoea & Cough & Fever & ARI* & Any illness \\
\hline I month & $4(1.5)$ & I 30 (47.8) & $50(18.4)$ & $4 \mid(15.0)$ & 157 (57.7) \\
\hline 2 month & $2(0.7)$ & 103 (37.9) & $57(21.0)$ & $46(16.9)$ & 132 (48.5) \\
\hline 3 month & $4(1.5)$ & $78(28.7)$ & $46(16.9)$ & $38(14.0)$ & $99(36.4)$ \\
\hline 4 month & $4(1.5)$ & $83(30.5)$ & $52(19.1)$ & $45(16.5)$ & $106(39.0)$ \\
\hline 5 month & $7(2.6)$ & $94(34.6)$ & $68(25.0)$ & $59(21.7)$ & $123(45.2)$ \\
\hline 6 month & $9(3.3)$ & $101(37.1)$ & $82(30.1)$ & $63(23.2)$ & 149 (54.8) \\
\hline
\end{tabular}

*Acute respiratory infection 


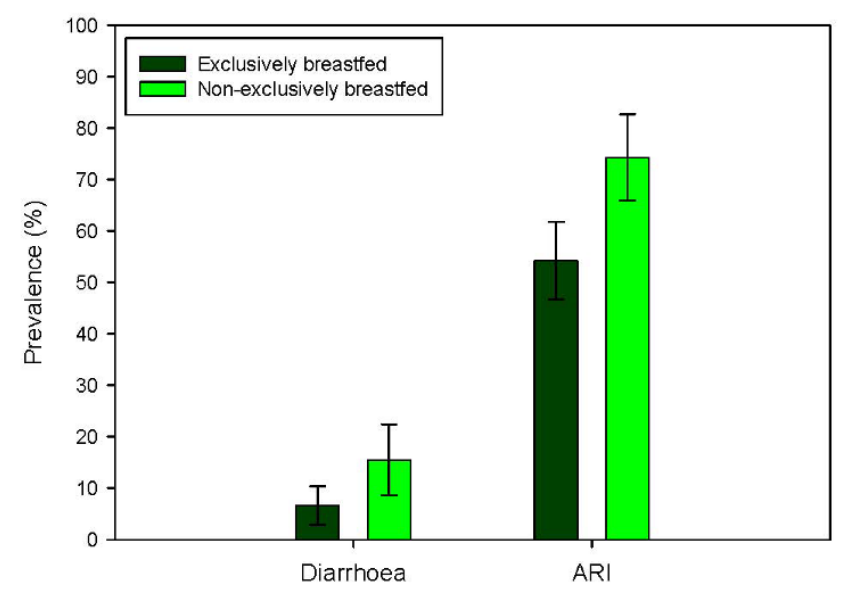

Figure 3

Prevalence of diarrhoea and acute respiratory infections (ARI) between infants exclusively breastfed and infants non-exclusively breastfed in the Chittagong cohort study (error bars represent $95 \%$ confidence intervals).

number of infants that didn't breastfeed, there was no non breastfed category for comparison in our study. In some studies the categories of partial and predominantly breastfed are merged into a 'mixed fed' category [9,10]. Other studies compare any breastfeeding with non breastfed [11], or compare exclusively breastfed infants with non exclusively breastfed infants [12] making it difficult to compare results of all studies according to outcomes.

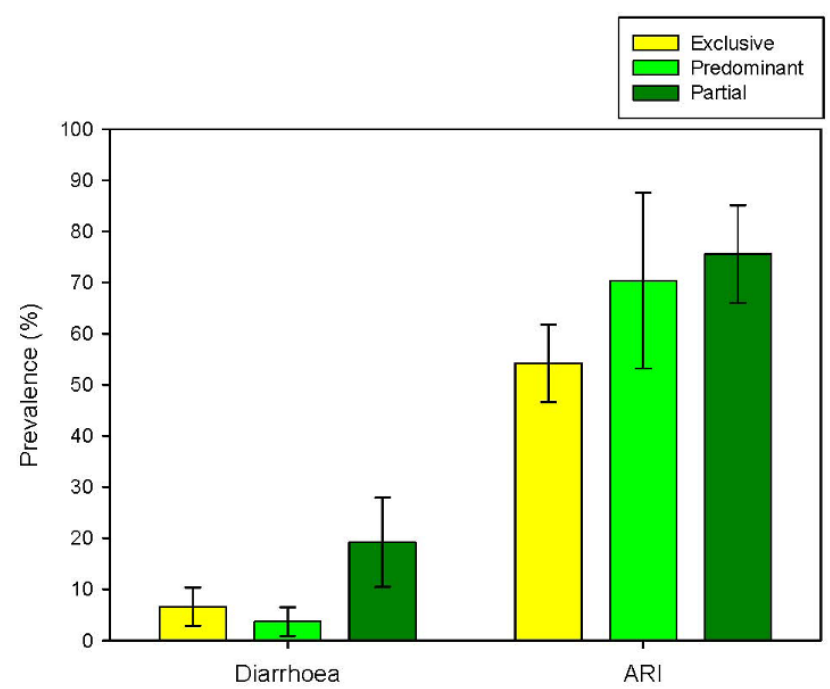

Figure 4

Prevalence of diarrhoea and acute respiratory infections (ARI) between infants according to patterns of breastfeeding in the Chittagong cohort study (error bars represent $95 \%$ confidence intervals).
There were no differences in morbidity patterns between infants who were exclusively breastfed and those who were predominantly breastfed (ie breastmilk and water based drinks but no infant formula/milk or solid food). It may be that in certain settings where purity of drinking water is good and standards of hygiene are high, predominant breastfeeding may be as safe as exclusive breastfeeding for the infant. However in countries such as Bangladesh, especially in rural areas these conditions are unlikely, so the results of this study are surprising. Some studies suggest that predominantly breastfed infants who have had tastes of water and honey have had damage to the mucosal lining of gastrointestinal tract leaving the infant more susceptible to infection [13], but this effect could not be confirmed in this cohort.

A limitation of this cohort study is that the definition of exclusive breastfeeding included some of those infants who had received prelacteal feeds, as long as the feeds were not given two successive days or more. If truly exclusively breastfed infants (ie. exclusively breastfed since birth) were compared to predominately breastfed infants, larger differences in infectious disease may have been seen. Another limitation was the differences between families who remained in the study for the six month period and those that withdrew. Families who stayed in the study were more likely to have a stable family structure (ie. husbands living at home, and owning their own home). They were more likely to have other children and a larger number of children although the overall family size, and therefore the likelihood of crowding, was similar. These factors are unlikely to have added considerable bias to the study results. There was no difference in gestational age or other characteristics between groups although the babies in the group that withdrew had a lower weight and length than those who stayed in the study. This may be an indication that the analysis included infants who were healthier.

Misclassification of the exposure was also a possibility. The category of breastfeeding (exclusive, predominant or partial) was classified at the six month visit while the outcome was measured at monthly visits to avoid recall bias. In order to minimize misclassification the outcomes and exposures in the first three months and last three months were combined and the results were similar to the grouped analysis. That is, that exclusive breastfeeding was not significantly more protective than predominant breastfeeding for preventing diarrhoeal illness or ARI although it was significantly more protective than partial breastfeeding.

The problem of reverse causality may be a limitation to this study. For example, if mothers tended to breastfeed 
Table 5: Association between patterns of breastfeeding and diarrhoea and acute respiratory infection in the Chittagong cohort

\begin{tabular}{lllll}
\hline Breastfeeding practice & \multicolumn{2}{c}{ Diarrhoea } & Acute respiratory infections \\
\cline { 2 - 5 } & AOR* $(95 \% \mathrm{Cl})$ & P value & AOR* $(95 \% \mathbf{C l})$ & P value \\
\hline Exclusive $(n=167)$ & 1.00 & 1.00 & 0.17 \\
\hline Predominant $(n=27)$ & $0.48(0.06,3.95)$ & 0.50 & $1.85(0.76,4.69)$ & $<0.01$ \\
\hline Partial $(n=78)$ & $3.43(1.47,8.03)$ & $<0.01$ & $2.49(1.34,4.63)$ & \\
\hline
\end{tabular}

* Adjusted Odds Ratio: adjusted for mother's education, asset score and husband living with family as a measure of socioeconomic status, type of latrine as a measure of sanitation, gender, other siblings.

exclusively because the child was ill, the effect of exclusive breastfeeding on illness would have been underestimated. Conversely, if mothers stopped breastfeeding as a result of illness this would have biased the results towards an overestimation of an effect. A way to minimize this would be to ascertain whether any of the mothers changed their breastfeeding behavior as a result of illness. Because of the generally high rates of continued exclusive breastfeeding, the assumption is that this would lead to an underestimation of any association with respect to illness.

Another limitation to the study is the high number of stillborn babies (9/351 or 2.6\%). This figure is typical of the rural population of Bangladesh where most women do not have access to antenatal care and almost $90 \%$ of women deliver at home without specialized delivery care.

The rates of prelacteal feeding and reasons for prelacteal feeding are consistent with other descriptive studies undertaken in rural Bangladesh [14,15]. There was a high rate of exclusive breastfeeding throughout the study with $87.1 \%$ of mothers exclusively breastfeeding at one month. The rate of exclusive breastfeeding gradually declined to $77.2 \%$ at three months and $61.4 \%$ at six months. Only one child in the whole cohort was not breastfed.

\section{Conclusion}

In summary, this cohort study conducted in Chittagong in Bangladesh has shown that infants who are exclusively breastfed from birth to six months of age have a significantly lower prevalence of diarrhoea and acute respiratory infection than those infants who are not exclusively breastfed. However, there were no differences in morbidity prevalence between infants who were exclusively breastfed or predominantly breastfed. The results of this study seem to suggest that both exclusive and predominant breastfeeding can reduce morbidity in this rural area of Bangladesh.

\section{Competing interests}

The authors declare that they have no competing interests.

\section{Authors' contributions}

IK was responsible for the study design, conduct and data collection, SM performed the data analysis, interpreted the data and prepared the manuscript. WO and JKP provided content advice, interpretation of data and statistical advice for the manuscript. All authors read and approved the final manuscript.

\section{Acknowledgements}

The authors would like to acknowledge the data collection team and mothers who participated in the study.

\section{References}

I. Baqui AH, Sabir AA, Begum N, Arifeen SE, Mitra SN, Black RE: Causes of childhood deaths in Bangladesh: an update. Acta Paediatr 2001, 90(6):682-690.

2. Mitra and Associates: Bangladesh Demographic and Health Survey. National Institute of Population Research and Training (NIPORT). Calverton: MEASURE/DHS+ Macro International; 2004.

3. Black RE, Morris SS, Bryce J: Where and why are 10 million children dying every year? Lancet 2003, 36 I (9376):2226-2234.

4. Arifeen S, Black RE, Antelman G, Baqui A, Caulfield L, Becker S: Exclusive breastfeeding reduces acute respiratory infection and diarrhea deaths among infants in Dhaka slums. Pediatrics 200I, 108(4):E67.

5. Haider R, Ashworth A, Kabir I, Huttly SR: Effect of communitybased peer counsellors on exclusive breastfeeding practices in Dhaka, Bangladesh: a randomised controlled trial. Lancet 2000, 356(9242): $1643-1647$.

6. Kabir AKMI, Haider R, Banu S, Faruque T, Firu FB: Impact of a less intensive peer counseling method in rural Bangladesh. In Breast-feeding: early influences on latter health: programme \& abstracts of the I 2th International Conference of the International Society for Research in Human Milk and Lactation, 10-14 September 2004 Cambridge University, Cambridge.

7. Bahl R, Frost C, Kirkwood BR, Edmond K, Martines J, Bhandari N, Arthur P: Infant feeding patterns and risks of death and hospitalization in the first half of infancy: multicentre cohort study. Bull World Health Organ 2005, 83(6):418-426.

8. WHO: Indicators for Assessing Breastfeeding Practices: Report of an informal meeting in June Geneva. World Health Organisation, Geneva; 1991.

9. Leung GM, Lam TH, Ho LM, Lau YL: Health consequences of breast-feeding: doctors' visits and hospitalizations during the first 18 months of life in Hong Kong Chinese infants. Epidemiology 2005, 16(3):328-335.

10. Kandala NB, Magadi MA, Madise NJ: An investigation of district spatial variations of childhood diarrhoea and fever morbidity in Malawi. Soc Sci Med 2006, 62(5): I I 38-I I 52.

II. Chompook P, Todd J, Wheeler JG, von Seidlein L, Clemens J, Chaicumpa W: Risk factors for shigellosis in Thailand. Int J Infect Dis 2006, I0(6):425-433.

12. Pathela P, Hasan K, Roy E, Huq F, Siddique A, Sack R: Diarrheal illness in a cohort of children 0-2 years of age in rural Bangla- 
desh: I. Incidence and risk factors. Acta Paediatr 2006, 95(4):430-437.

13. Edmond KM, Kirkwood BR, Amenga-Etego S, Owusu-Agyei S, Hurt LS: Effect of early infant feeding practices on infection-specific neonatal mortality: an investigation of the causal links with observational data from rural Ghana. Am J Clin Nutr 2007, 86(4): || $26-|| 3 \mid$.

14. Haider R, Kabir I, Hamadani JD, Habte D: Reasons for failure of breast-feeding counselling: mothers' perspectives in Bangladesh. Bull World Health Organ 1997, 75(3): 191-196.

15. Das DK, Talukder MQ, Sella GE: Infant feeding practices in rural Bangladesh. Indian J Pediatr 1992, 59(5):573-577.

Publish with Bio Med Central and every scientist can read your work free of charge

"BioMed Central will be the most significant development for disseminating the results of biomedical research in our lifetime. "

Sir Paul Nurse, Cancer Research UK

Your research papers will be:

- available free of charge to the entire biomedical community

- peer reviewed and published immediately upon acceptance

- cited in PubMed and archived on PubMed Central

- yours - you keep the copyright

Submit your manuscript here:

http://www.biomedcentral.com/info/publishing_adv.asp
BioMedcentral 